\title{
Projected impacts of climate warming on the functional and phylogenetic components of coastal Mediterranean fish biodiversity
}

C Albouy

F Leprieur

F Le Loc'h

$\mathrm{N}$ Mouquet

CN Meynard

Virginia Institute of Marine Science

See next page for additional authors

Follow this and additional works at: https://scholarworks.wm.edu/vimsarticles

Part of the Aquaculture and Fisheries Commons

\section{Recommended Citation}

Albouy, C; Leprieur, F; Le Loc'h, F; Mouquet, N; Meynard, CN; and Et al., Projected impacts of climate warming on the functional and phylogenetic components of coastal Mediterranean fish biodiversity (2015). Ecography, 38(7), 681-689.

$10.1111 /$ ecog. 01254

This Article is brought to you for free and open access by the Virginia Institute of Marine Science at W\&M ScholarWorks. It has been accepted for inclusion in VIMS Articles by an authorized administrator of W\&M ScholarWorks. For more information, please contact scholarworks@wm.edu. 
Authors

C Albouy, F Leprieur, F Le Loc'h, N Mouquet, CN Meynard, and Et al. 


\title{
Projected impacts of climate warming on the functional and phylogenetic components of coastal Mediterranean fish biodiversity
}

\author{
Camille Albouy, Fabien Leprieur, François Le Loc'h, Nicolas Mouquet, Christine N. Meynard, \\ Emmanuel J. P. Douzery and David Mouillot
}

C. Albouy (albouycamille@gmail.com), F. Leprieur, and D. Mouillot, Laboratoire Ecologie des Systèmes Marins Côtiers UMR 5119, CNRS, IRD, IFREMER, UMII, UMI, cc 093, Place E. Bataillon, FR-34095 Montpellier Cedex 5, France. CA also at: Dépt de biologie, chimie et géographie, Univ. du Québec à Rimouski, 300 Allée des Ursulines, QC G5L 3A1, Canada. DM also at: ARC Centre of Excellence for Coral Reef Studies, James Cook Univ., Townsville, QLD 4811, Australia. - F. Le Loc'h and CA, Laboratoire Ecosystèmes Marins Exploités UMR 212, IRD, IFREMER, UMII, avenue Jean Monnet BP171, FR-34203 Sète Cedex, France. FL also at: Laboratoire des Sciences de l'Environnement Marin, UMR 6539 CNRS, UBO, IRD, IFREMER, Inst. Univ. Européen de la Mer, Technopôle Brest-Iroise, Rue Dumont d'Urville, FR-29280 Plouzané, France. - N. Mouquet and E. J. P. Douzery, Inst. des Sciences de l'Evolution, UMR CNRS, IRD, UM2 5554, Univ. Montpellier 2, Place Eugène Bataillon, FR-34095 Montpellier, France. - C. N. Meynard, Centre de Biologie pour la Gestion des Populations, UMR INRA, IRD, Cirad, Montpellier SupAgro, Campus International de Baillarguet, CS 30016, FR-34988 Montferrier-sur-Lez Cedex, France, and Virginia Inst. of Marine Science, College of William and Mary, Po Box 1346, Gloucester Point, VA 23062, USA.

\begin{abstract}
Climate warming affects biodiversity distribution across all ecosystems. However, beyond changes in species richness, impacts on other biodiversity components are still overlooked, particularly in the marine realm. Here we forecasted the potential effect of climate warming on the phylogenetic and functional components of coastal Mediterranean fish biodiversity. To do so, we used species distribution models to project the potential distribution of 230 coastal fish species by the end of the 21 st century based on the IPCC A2 scenario implemented with the Mediterranean climatic model NEMOMED8. From these projections, we assessed the changes in phylogenetic (PD) and functional diversity (FD) of fish assemblages at multiple spatial scales using a dated molecular phylogeny and an extensive functional trait database. At the scale of the entire Mediterranean Sea, the projected extinctions of 40 coastal fish species would lead to a concomitant erosion of PD and FD (13.6 and 3\%, respectively). However, a null model revealed that species loss at this scale would not lead to a disproportionate erosion of PD and FD. Similar results were found when considering fish assemblages at the grid cell scale. Indeed, at this scale, the projected changes in species richness would lead to unexpected losses of PD and FD for localized and small areas only. A disproportionate erosion of PD under climate warming was only forecasted when analysing fish assemblages at an intermediate spatial scale, namely the Mediterranean marine ecoregions. Overall, our results emphasize the importance of considering multiple spatial scales when assessing potential impacts of climate warming on the multiple components marine biodiversity.
\end{abstract}

In the past 540 million years five major extinction crises have occurred resulting in the loss of more than three-quarters of the species on Earth during each (Barnosky et al. 2011). Today the sixth extinction crisis is taking place, considered to be mediated by habitat fragmentation, introduction of non-native species, harvesting of natural resources and climate change (Barnosky et al. 2011, Thuiller et al. 2011). Beyond the accumulated evidence that ecosystems are rapidly losing species worldwide, the amount of phylogenetic (lineages) and functional (traits) diversity being lost is still under scrutiny. The loss of species with unique traits or belonging to sparse lineages, may markedly affect ecosystem functioning (Cadotte et al. 2008), especially when multiple functions are considered (Mouillot et al. 2011a). This assumption is based on experiments showing that species with unique combination of traits can regulate ecosystem processes (Norling et al. 2007) and that trait dissimilarity within species assemblages increases ecological process rates
(Mouillot et al. 2011b). Even if all the species traits cannot fully described the species roles in an ecosystem, the amount of phylogenetic diversity within an assemblage has been shown to explain ecosystem productivity (Cadotte et al. 2008) and stability (Cadotte et al. 2012). It is therefore critical to know the extent to which phylogenetic diversity (PD) and functional diversity (FD) are eroded, beyond knowing the species diversity loss.

Previous studies have investigated climate change impacts on the erosion of the tree of life (Thuiller et al. 2011) or on the breadth of functional roles played by species assemblages (Naeem et al. 2012, Thuiller et al. 2014), but none have integrated these components simultaneously. Furthermore, our understanding of climate change impacts on marine ecosystems still lags far behind with respect to terrestrial ecosystems (Robinson et al. 2011) partly due to the size and the complexity of the oceans but also to the relative difficulty of data collection. The recent coupling between 
regional oceanographic models such as NEMOMED 8 (Beuvier et al. 2010) and species distribution modeling approaches using the modeling platform BIOMOD (Thuiller et al. 2009) provide a first step towards the assessment of climate warming impacts on marine assemblages and ecosystem functioning in the Mediterranean Sea (Ben Rais Lasram et al. 2010, Albouy et al. 2013). However this framework has not yet been used to investigate the expected changes in marine phylogenetic and functional diversity under climate warming.

Here we projected the potential effect of climate warming on future PD and FD diversities in Mediterranean fish assemblages using the geographical distributions of 230 strictly coastal teleost species (Albouy et al. 2013), and a regional model of oceanographic circulation (NEMOMED8) based on a SRES (Special Report on Emissions Scenarios) A2. We first estimated the changes in PD and FD of coastal fish assemblages between present-day and the end of the 21 st century at three nested spatial scales: 1) the whole Mediterranean coastal area, 2) the Mediterranean marine ecoregions and 2) the 8154 cells $\left(0.1^{\circ} \times 0.1^{\circ}\right)$ of the Mediterranean continental shelf. To do so, we used classical measures of both phylogenetic and functional diversity namely the PD (Faith 1992) and FD (Petchey and Gaston 2002) indices. The PD index relies on the amount of evolutionary history (based on branch length of a phylogenetic tree) represented by a set of species and the potential for future diversification. FD represents the extent of the functional differences among species based on the distinction of their morphological, physiological and ecological traits (Petchey and Gaston 2006). Last, to identify areas with unexpected changes in PD and FD, we built a null model to assess the extent to which the changes in PD and FD differed from those expected by the changes in species richness (SR).

\section{Material and methods}

\section{Species data}

The geographical distributions of 230 coastal Mediterranean fish species were compiled from the published atlas of fishes of the northern Atlantic and the Mediterranean (FNAM). This atlas is based on regional data sets and expert knowledge and was edited between 1984 and 1986. It currently provides the only available basin-wide information on the extent of occurrence of all Mediterranean fish species. We therefore refined the extent of occurrence maps by removing from analysis areas with depths that fall outside the minimum or maximum known for the species. Species' bathymetric ranges were obtained from FishBase (Froese and Pauly 2012) and from Louisy (2005). The bathymetry of the Mediterranean Sea was obtained from the ETOPO2v2 Global Gridded 2-minute Database (ETOPO2v2 2010).

We restricted our analyses to the continental shelf of the Mediterranean Sea (200 m depth limit) for two reasons. First, major threats such as fishing pressure are mainly concentrated on the coast (Coll et al. 2010). Second, climate change is more likely to affect coastal species (Lloyd et al. 2012), which do not benefit from the temperature inertia of deep waters (Stefansdottir et al. 2010). Exotic species were discarded from our analyses because the equilibrium with environmental conditions is a required assumption for predicting and projecting species distributions (Guisan and Thuiller 2005). Our final data set summarizes the occurrences of 230 strictly coastal fish species on a $0.1^{\circ}$ resolution grid system covering the continental shelf of the Mediterranean Sea (8154 cells).

\section{Current and projected sea surface temperatures}

We used a regional marine model of oceanographic circulation (NEMOMED8) that predicts sea surface temperature (SST) based on the following drivers: water energy fluxes, river discharges and water exchanges with the surrounding seas (Beuvier et al. 2010). This model covers the whole Mediterranean Sea and a buffer zone which includes a part of the Atlantic Ocean. The horizontal resolution of NEMOMED8 is $1 / 8^{\circ}$ longitude, resulting in square gridcells of $9-12 \mathrm{~km}$ depending on the latitude. NEMOMED8 is a Mediterranean configuration of the NEMO ocean model and can be seen as an ameliorated version of the OPAMED8 model (Somot et al. 2006). Technical details about NEMOMED8 can be found in Beuvier et al. (2010).

We used daily SST values predicted by NEMOMED8 from the period 1961-1980 as a baseline to calibrate the species distribution models (Beuvier et al. 2010). The daily data were averaged to infer monthly data, leading to 15 variables: 12 monthly averaged SST values, the absolute minimum SST, the absolute maximum SST and the absolute range of SST (i.e. the difference between the absolute maximum and minimum SST). Several SST variables were considered because fish are ectothermic and thus highly dependent on the precise characteristics of their thermal environment for breeding and developmental success (Mann and Blackburn 1991). For instance, larvae and juvenile recruitment is strongly dependent on maximum temperatures (Burreson and Sypek 1981).

However, to avoid model over-parameterization and reduce collinearity among predictor variables (Thuiller 2004), we removed redundant temperature variables. To do so, we reduced the set of predictive variables on the basis of a k-means partitioning method. The optimal number of groups was determined according to the highest simple structure index (SSI), following Dolnicar et al. (1999). We obtained eight synthetic variables by averaging inside each group determined by the k-means clustering. Projected SST values were obtained from NEMOMED8 for the end of the 21st century (2080-2099) according to the IPCC A2 scenario. The A2 scenario is a standard for regional climate studies and it is the only available scenario implemented by NEMOMED8.

Large-scale patterns of fish species distributions in marine ecosystems are constrained by several limiting factors (Dambach and Roedder 2011). Among them, water temperature is recognized as one of the main drivers shaping fish species distributions (Dulvy et al. 2008). To investigate this assumption, we conducted an outlying mean index analysis (OMI; Doledec et al. 2000), which identifies the main environmental variables separating species distribution. This analysis using both SST and SSS (sea surface salinity) variables confirmed that the SST variables were most 
important for explaining fish species distribution characteristics (for more details see Albouy et al. 2013). In addition, the ranges and thresholds of SST have been shown to explain endemic fish distributions in the Mediterranean Sea (Ben Rais Lasram et al. 2009). SST variables were therefore used as the sole predictors of fish species distribution in the present study.

\section{Species distribution modelling}

We implemented an ensemble forecasting approach to account for uncertainty in the outcomes of different SDM methods (Araújo and New 2007). Fish species distributions were modelled using seven different SDM methods: 1) generalized linear models (GLM), 2) generalized additive models (GAM), 3) classification tree analysis (CTA), 4) random forests (RF), 5) boosted regression trees (BRT), 6) multivariate adaptive regression splines (MARS) and 7) surface range envelope (SRE). Modelling was performed with the BIOMOD R-package (Thuiller et al. 2009).

We applied a cross-validation procedure to avoid circularity when the same data are used to construct and evaluate the model. For each species, models were calibrated using a random sample of the initial data $(80 \%)$. Then, each model was evaluated on the remaining $20 \%$ of the initial data set using the true skill statistic (TSS) criterion (3-fold cross validation). We based our evaluation on TSS, as recommended by Allouche et al. (2006). TSS scores were interpreted following the Landis and Koch (1977) accuracy classification scheme. For a given species the predicted presences/absences were derived from the predicted probabilities of occurrence using the threshold that maximized the TSS (Thuiller et al. 2009). The predictive accuracy was classified as 'fair' to 'good' for the seven SDMs, with a mean TSS of 0.61. However, overall no clear evidence of model superiority emerged. We therefore implemented ensemble forecasts (weighted average consensus) to project potential thermal niches in the future. Alternative SDMs may provide markedly different projections for the same data set, and model evaluation often cannot demonstrate which projection is superior (Araújo and New 2007). To overcome these limitations, we used the weighted average consensus (WAC) method to take into account model-based uncertainty (Thuiller et al. 2009).

Using the projected temperatures for 2040-2059 and 2080-2099, we predicted the geographic location of the potential suitable SST (as inferred by the ensemble forecasts) for each species. We assumed unlimited dispersal towards new climatically suitable areas because invasions show that fish may reach a mean dispersal rate of $221+/-5.4 \mathrm{~km}$ $\mathrm{yr}^{-1}$ on the northern side of Mediterranean Sea (Ben Rais Lasram et al. 2008). However, we imposed some bathymetric limitations by not allowing a species to be present in a cell if that cell's depth did not conform to the species' known current bathymetric range.

\section{Phylogenetic and functional diversity of fish assemblages}

The phylogenetic relationships between the 230 species were extracted from a dated phylogeny (Meynard et al. 2012) built from a DNA super matrix composed of four mitochondrial genes (12S ribosomal DNA, $16 S$ ribosomal DNA, cytochrome c oxidase subunit I and cytochrome) and two nuclear genes (rhodopsin and recombination activating gene I). The phylogeny included $62 \%$ of Mediterranean teleost species plus 9 out-groups to build a dated phylogeny. For each fish assemblage we computed phylogenetic diversity using the PD index (Faith 1992) which relies on the amount of evolutionary history (based on branch length on a phylogenetic tree) represented by a set of species.

We compiled information for the 230 species on the following 10 traits to calculate functional diversity: maximum length, vertical distribution, habitats (rocky, soft, and posidonia seagrass), migration, reproduction, semelparity, sex shift, larvae types, species behavior (gregarious, solitary, or both), and diet, based on different sources ( $<$ fishbase.org $>$; Froese and Pauly 2012, Supplementary material Appendix 1). To quantify functional diversity, we used the method proposed by Petchey and Gaston (2006) by computing a functional dendrogram based on Gower's distance between each pair of species and the UPGMA linkage method. Gower's distance allows mixing variables of different natures while giving them equal weight (Legendre and Legendre 1998) and the UPGMA linkage method was found to produce the most faithful representation (i.e. a dendrogram) of the initial distance matrix (Merigot et al. 2010). We also performed a principal coordinates analysis (PCoA) based on Gower's distance matrix to identify the position of each species in the multidimensional functional space (Buisson et al. 2013).

\section{Projections of biodiversity components under climate warming}

To derive future patterns of phylogenetic and functional diversity, we applied an assemblage-level analysis (the 'predict first, assemble later' strategy from Ferrier and Guisan 2006), which consists in building a presence/absence matrix for the future period by aggregating the projected species distribution of each species. Overall, we built three presence/absence matrices, each of them corresponding to three nested spatial scales: 1) the whole continental shelf of the Mediterranean Sea, 2) the 7 marine ecoregions described by Spalding et al. (2007) and 3) the 8154 grid cells. Based on the phylogenetic tree (Fig. 1a) and the functional dendrogram (Fig. 1b), we quantified phylogenetic and functional diversity for the current (1961-1980) and future (2080-2099) periods for each spatial scale. We used two well-known metrics, the phylogenetic diversity (PD) measure (Faith 1992) and its functional counterpart (FD; Petchey and Gaston 2006). We calculated the absolute changes in species richness, FD and $\mathrm{PD}(\triangle \mathrm{SR}, \triangle \mathrm{FD}$ and $\triangle \mathrm{PD})$ between the current and future periods as well as the relative changes in $\mathrm{SR}\left(\left(\mathrm{SR}_{\text {future }}\right.\right.$ $\left.\left.-\mathrm{SR}_{\text {current }}\right) / \mathrm{SR}_{\text {current }}\right), \mathrm{FD}\left(\left(\mathrm{FD}_{\text {future }}-\mathrm{FD}_{\text {current }}\right) / \mathrm{FD}_{\text {current }}\right)$ and $\mathrm{PD}\left(\left(\mathrm{PD}_{\text {future }}-\mathrm{PD}_{\text {current }}\right) / \mathrm{PD}_{\text {current }}\right)$ expressed as percentage.

The PD and FD metrics are intrinsically highly dependent on species richness (Winter et al. 2013). We therefore implemented a null model to assess the extent to which $\triangle \mathrm{PD}$ and $\Delta \mathrm{FD}$ differed from that expected by $\Delta \mathrm{SR}$ only (i.e. to what extent the projected changes in species richness led 

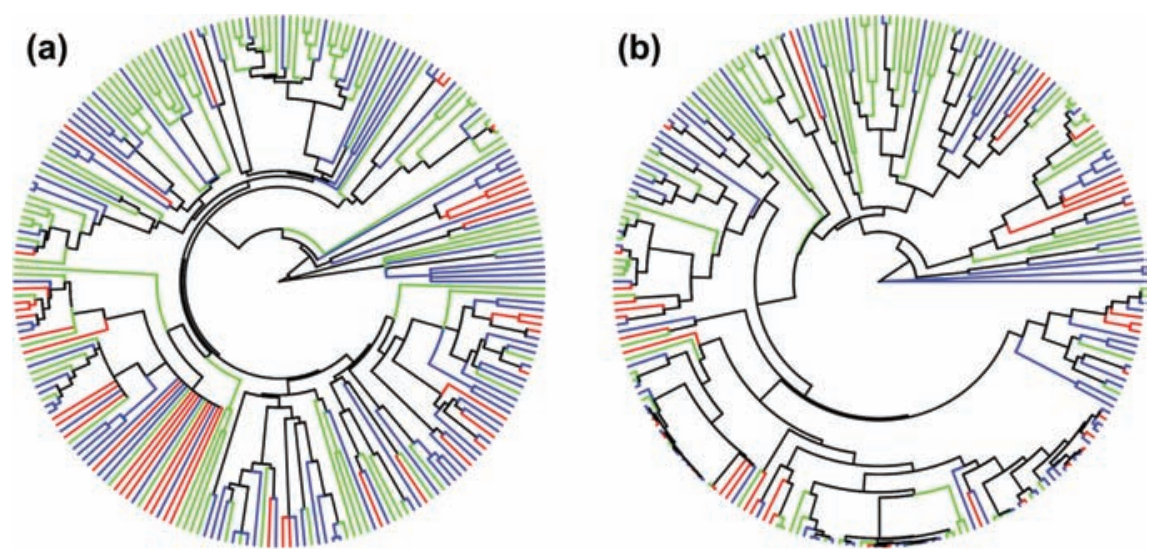

Figure 1. Changes in suitable climate (A2 scenario for 2080-2099) mapped onto the phylogenetic (a) and functional trees (b) of coastal Mediterranean fishes. Green edges indicate a range expansion, other colours indicate range contraction: blue for a decrease and red for extinction.

to unexpected changes in PD and FD). We first quantified PD (and FD) for the future period after having randomized the species identities across the tips of the phylogeny (and functional dendrogram). Only species lost and/or gained between the current and future time periods were considered in this null model, as species common to the two periods were not affected by climate warming. We then quantified the absolute (and relative) change in PD (and FD) between the current and future time periods. We repeated this randomization procedure 999 times to obtain a null distribution of $\triangle \mathrm{PD}$ (and $\triangle \mathrm{FD}$ ). During the randomization procedure, the projected species richness for the future period is kept constant and equal to the observed species richness. Last, we compared the observed $\triangle \mathrm{PD}$ (and $\triangle \mathrm{FD}$ ) values to the null distribution using a tailed test and two significance levels $(\alpha=5$ and $10 \%)$.

\section{Results}

Based on observed fish distributions $(\mathrm{n}=230)$ and baseline SST predictor values, the predictive accuracy of the seven different SDM methods was classified as 'fair' to 'good' with a mean TSS of 0.61. The least accurate method was SRE with a mean TSS of 0.4 whereas the most accurate was CTA with a mean TSS of 0.71 . According to the predictions of the IPCC A2 scenario implemented in the climatic model, mean SST would experience an average increase of $2.8^{\circ} \mathrm{C}$ over the whole Mediterranean Sea at the end of the 21st century.
Among the 230 modeled species, projections predicted that 140 species might experience a reduction in their suitable thermal conditions and 40 species might have no suitable thermal conditions remaining (Fig. 1 and Table 1), while 90 species might expand their suitable thermal conditions on the continental shelf by 2080-2099. Among the species that might have no suitable thermal conditions, $50 \%$ were endemic to the Mediterranean Sea, and $85.5 \%$ were listed on the IUCN Red List. The most represented family among potential extinct species was the Gobiidae with $40 \%$ of the species with no climatically suitable areas remaining (Fig. 1) following by the Blenniidae (10\%) and the Gadidae (7.5\%) families.

PD would decrease by $13.6 \%$ between the current period and the end of the present century; i.e. $13.6 \%$ of cumulative phylogenetic history for Mediterranean fish would be lost. This amount of PD reduction did not differ from that expected by the decrease in species richness only $(\mathrm{p}=0.39)$. FD would decrease by $3 \%$ between the observed period and the end of the present century (Fig. 2), which is significantly lower than expected by the decrease in species richness only $(\mathrm{p}=0.007)$.

Focusing on the Mediterranean ecoregions revealed that the most important decrease in species richness would be observed in the Ionian $(-25.5 \%)$ and Adriatic $(-21.8 \%)$ Seas followed by the western Mediterranean (-17.5\%; Fig. 3 and Table 1). We found that PD and FD of fish assemblages would be lower at the end of the current century in all ecoregions except in the Aegean Sea (Fig. 3). The largest decrease in PD

Table 1. Number of species lost, gained, and, remaining under climate between the baseline (1961-1980) and the modelled period (2080-2099) for the seven Mediterranean ecoregions.

\begin{tabular}{lcccc}
\hline Ecoregions & $\begin{array}{c}\text { Species } \\
\text { lost }\end{array}$ & $\begin{array}{c}\text { Species } \\
\text { gained }\end{array}$ & $\begin{array}{c}\text { Remaining } \\
\text { species }\end{array}$ & $\begin{array}{c}\text { Absolute difference } \\
\text { in species richness }\end{array}$ \\
\hline Mediterranean Sea & 40 & 0 & 190 & 40 \\
Adriatic Sea & 55 & 15 & 128 & 40 \\
Aegean Sea & 27 & 12 & 145 & 5 \\
Alboran Sea & 40 & 9 & 138 & 24 \\
lonian Sea & 57 & 0 & 131 & 48 \\
Levantine Sea & 21 & 18 & 134 & 21 \\
Tunisian/Gulf of Sidra & 35 & 3 & 118 & 17 \\
Western Mediterranean Sea & 41 & & 176 & 38 \\
\hline
\end{tabular}




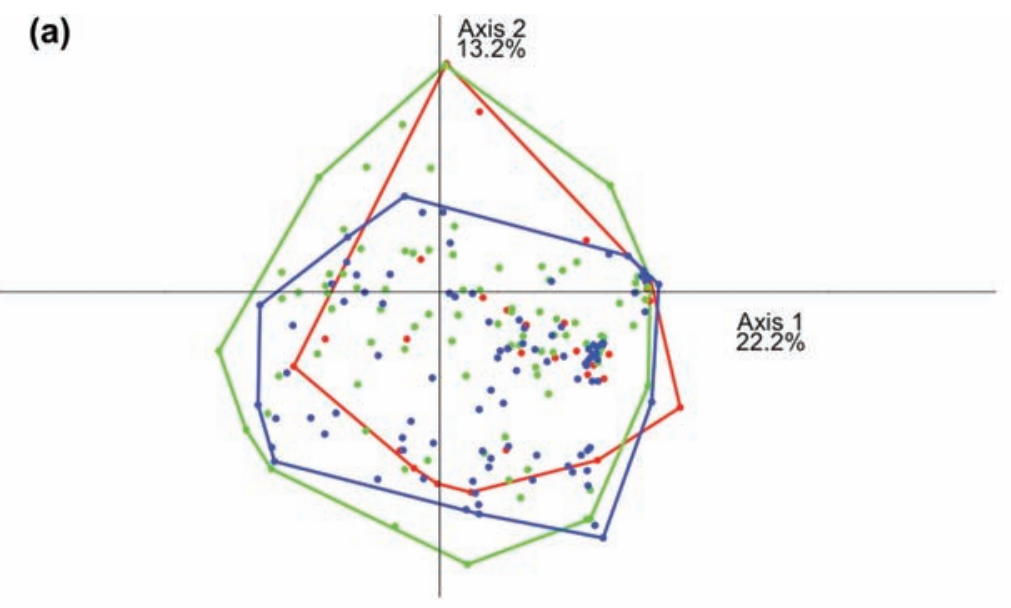

(b)

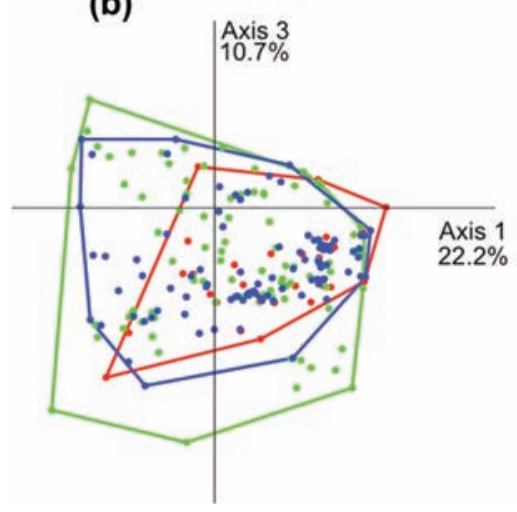

(c)

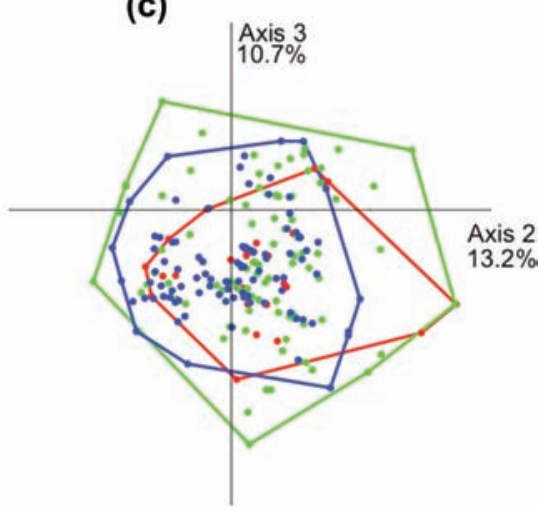

Figure 2. Changes in suitable climate (A2 scenario for 2080-2099) mapped onto the functional space of coastal Mediterranean fish. Polygons represent the functional spaces occupied by 1) species that expand their range in green, 2) species that contract their range (blue), and species that lost their range in red. The functional space was represented in (a) with the first and the second PCOA axes, in (b) with the first and the third PCOA axes, in (c) with the second and the third axes.

would be observed in the Ionian $(-18.2 \%)$ and Adriatic Seas $(-15.4 \%)$. Null models show that PD reduction would be higher than expected given the decrease in species richness, albeit only marginally significant $(0.05<p<0.1)$, in the Alboran $(p=0.076)$, western Mediterranean $(p=0.067)$ and the Levantine Sea $(p=0.062)$. The largest decrease in

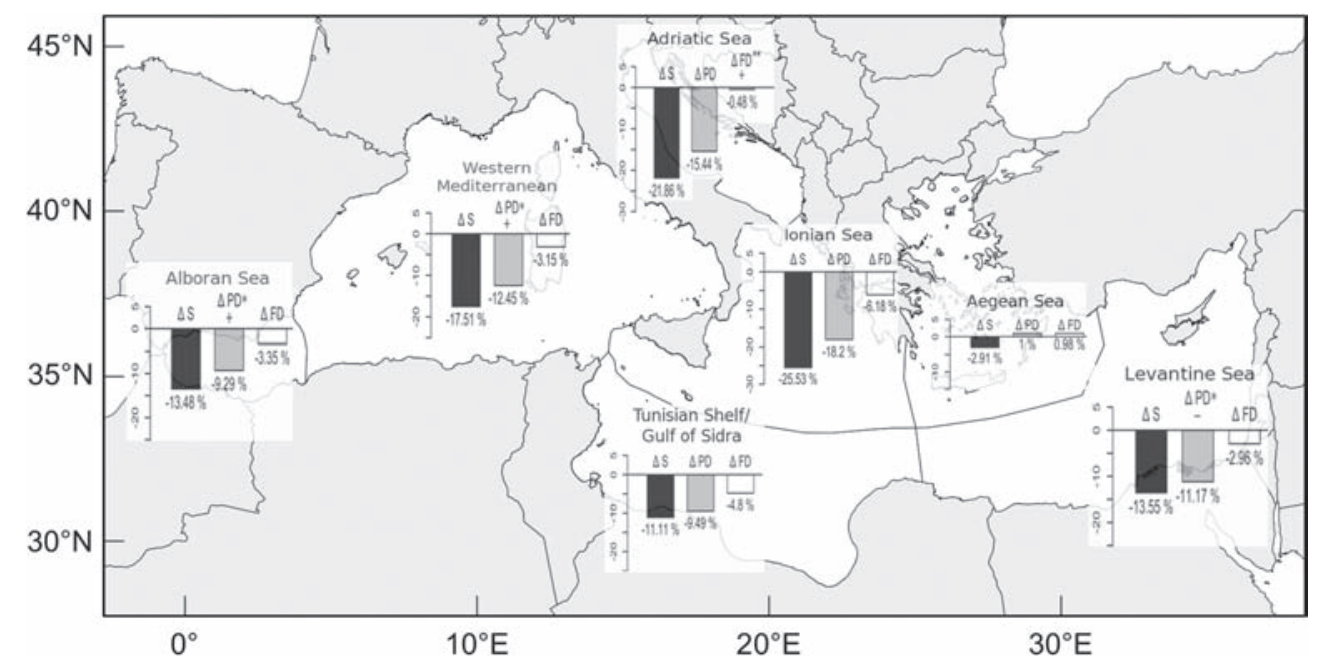

Figure 3. Relative changes in species richness (relative $\Delta \mathrm{SR}$ ), phylogenetic (relative $\Delta \mathrm{PD}$ ), and functional diversity (relative $\Delta \mathrm{FD}$ ), of coastal fish assemblages between the baseline (1961-1980) and the modelled period (2080-2099) for the seven Mediterranean ecoregions. When the difference in phylogenetic $(\triangle \mathrm{PD})$ or functional $(\triangle \mathrm{FD})$ diversity is significantly different from that expected by the null model (see Material and methods for more details), the stars indicate the significance level $\left({ }^{*} \mathrm{p}<0.1{ }^{* *} \mathrm{p}<0.05\right)$. The signs, ' + ' or ' - ', indicate whether the change in phylogenetic or functional diversity is higher or lower than expected by the change in species richness only. 
(a)

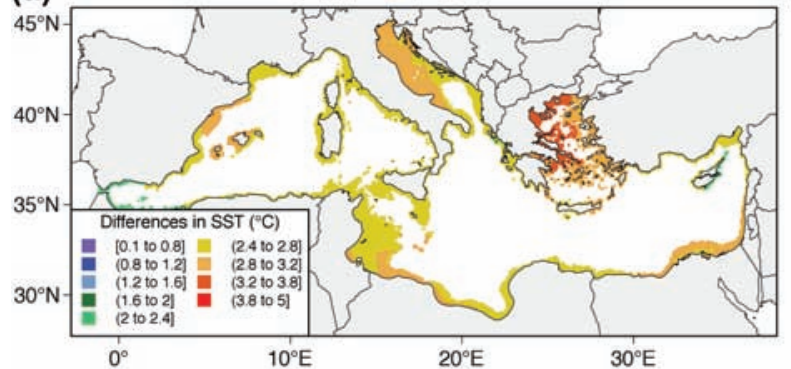

(c)

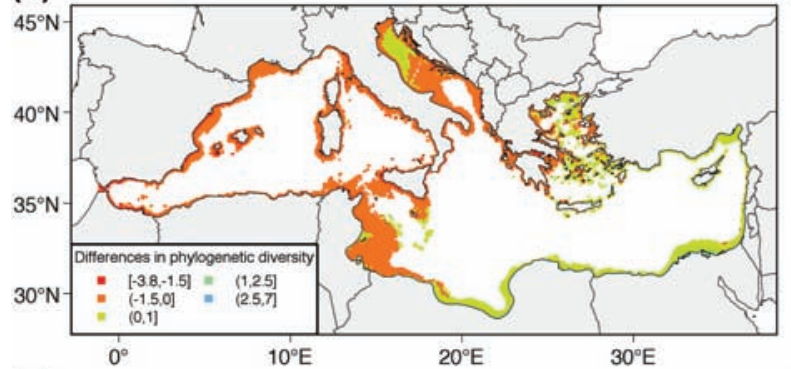

(e)

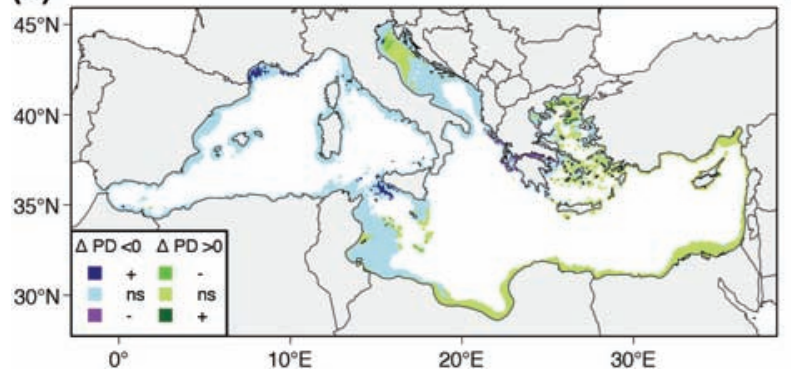

(b)

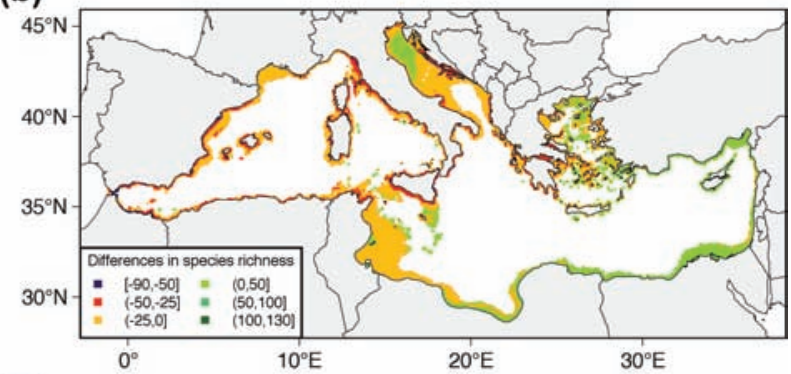

(d)

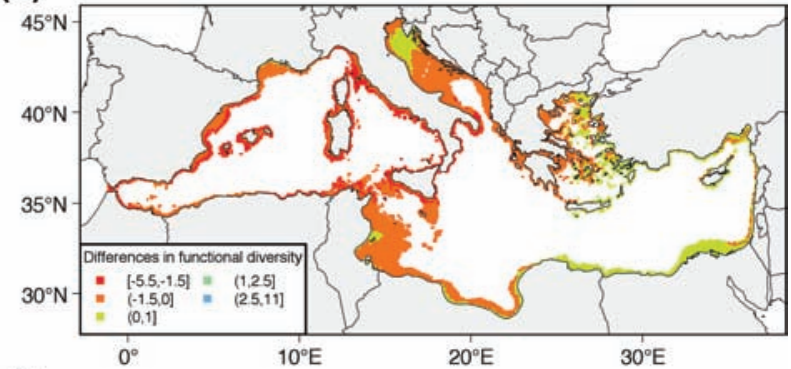

(f)

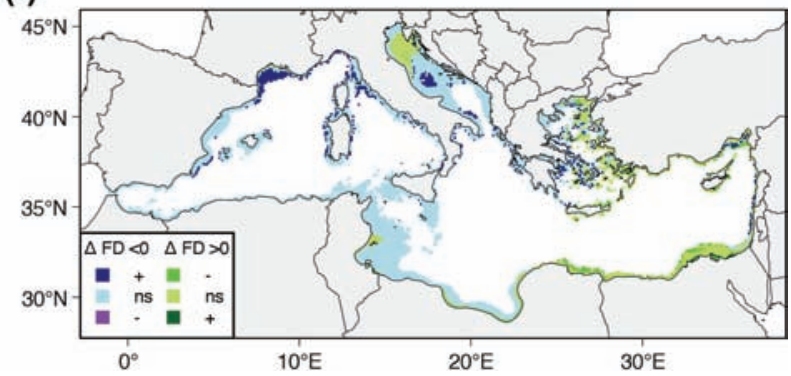

Figure 4. Mediterranean maps showing the net differences in: (a) mean sea surface temperature $\left(\mathrm{SST},{ }^{\circ} \mathrm{C}\right)$; (b) fish species richness; $(\mathrm{c})$ fish phylogenetic diversity; (d) fish functional diversity between the baseline scenario (1961-1980) and the future time period (2080-2099) predicted for the continental shelf of the Mediterranean Sea according the A2 scenario implemented in the NEMOMED8 climatic model. Significance of the change in phylogenetic (e) or functional diversity (f) according to a null model (see Material and methods for more details). The ' + ' symbol indicates that the changes in phylogenetic or functional diversity are significantly greater than expected by the null model ( $\mathrm{p}>0.975)$, whereas the '-' symbol indicates that observed differences in phylogenetic or functional diversity are significantly lower than expected by the null model $(\mathrm{p}<0.025)$. ns indicates that the changes in phylogenetic or functional diversity are not significantly different from that expected by the null model.

FD would be observed for the Ionian Sea and Tunisian shelf/ Gulf of Sidra ecoregions ( -6.2 and $-4.8 \%$, respectively, Fig. 3). The decrease in FD was found to be higher than expected by the decrease in species richness for the Adriatic Sea ecoregion only ( $p=0.0157$, Fig. 3).

At a smaller spatial scale, $70.4 \%$ of cells across the Mediterranean shelf were projected to lose species by 2080 2099 , with the largest loss being projected in the western Mediterranean Sea and in several parts of the Aegean and Adriatic Seas. Conversely, the largest species richness gains were projected in the Levantine Basin and in small areas of the North Adriatic Sea (Fig. 4b). By 2080-2099, 68.7 and $72.8 \%$ of the continental shelf would experience a decrease in PD and FD of fish assemblages, respectively (Fig. 4c, d), with a marked west-east spatial gradient. However, the null model revealed that only 1.31 and $7.4 \%$ of cells showed a decrease in PD and FD, respectively, than that expected given the decrease in species richness only. These cells are located in the western part of the Mediterranean Sea, i.e. the Gulf of Lion and southern Sicilia (Fig. 4e, f). In contrast,
1.9 and $0.04 \%$ of cells displayed a lower decrease in PD and FD, respectively, than that expected by the decrease in species richness only. These cells are located in the Gulf of Lion and the Adriatic Sea (Fig. 4f; for $\alpha=0.1$, see Supplementary material Appendix 2).

\section{Discussion}

Studying changes in species richness is a logical starting point to understand climate warming impacts, yet these changes may hide other aspects of biodiversity loss that are important to consider (Thuiller et al. 2011, 2014, Buisson et al. 2013, Cadotte et al. 2013). Our results highlight the importance of investigating changes in species assemblage composition from different angles, beyond simple metrics that ignore biological differences between species related to their evolution or their functional traits. We found that climate warming would lead to a decrease of fish species richness at all spatial scales considered (i.e. from the whole Mediterranean Sea to 
the grid cell), which may in turn induce a decrease in PD and FD. Using a null model approach, we also assessed whether the projected changes in species richness led to disproportionate changes in PD and FD. However, we acknowledge that our projections should be interpreted cautiously as our modelling framework does not provide a holistic view of processes affecting fish species distributions (Robinson et al. 2011). For instance, we did not take into account species interactions or environmental stressors such as water eutrophication and fisheries overexploitation that may mitigate or amplify the projected changes in species distribution at large spatial scales. In addition we only considered fish species distributions over the continental shelf to overcome the problem of high temperature variability across depth layers that characterize the open oceanic environment (Dambach and Roedder 2011). Arguably, compared to their terrestrial counterparts, estimating marine species climatic distributions is a more challenging task since the marine realm is a three-dimensional habitat. The bathymetric distribution is a third component to consider when modelling marine fish species distributions as different environmental factors (e.g. temperature, oxygen) are likely to influence habitat suitability at different depth ranges (Dambach and Roedder 2011). This implies that marine species may respond to water warming not only with a horizontal movement, but also with a vertical shift (Dulvy et al. 2008). These limitations could lead to an overestimation of the species potentially threatened by climate warming at the end of the 21 st century. However, it is worth nothing that most of these species (85.5\%) are already listed on the IUCN Red List. Overall, our results should be interpreted as a preliminary attempt to forecast the strength of temporal changes in functional and phylogenetic diversities for coastal fish assemblages facing climate warming.

At the scale of the Mediterranean Sea, our results showed that the loss of PD (14.6\%) projected under climate warming did not differ from that expected under a model of random extinctions across the phylogeny. This means that fish extinctions would not lead to a disproportionate loss of evolutionary history at this scale, a result also found by Thuiller et al. (2011) for plants and birds in Europe. Indeed, the 40 fish species projected to disappear at the end of the 21 st century were not clustered into a single clade with long branches, although many of them belong to the Gobiidae family (Fig. 1a). In contrast, taking into account functional differences between species instead of evolutionary relationships revealed a slight projected loss of FD (3\%), which tends to generalize the results obtained by Thuiller et al. (2014) on the European avifauna. This projected erosion of FD was also found to be lower than expected given random fish extinctions, hence suggesting that climate warming-induced fish extinctions would lead to an attenuated erosion of FD at the Mediterranean Sea scale. This can be explained by the high degree of functional redundancy between loser and winner species (Fig. 1b) that provides a buffer against the effect of potential species extinctions on the diversity of functional traits (Naeem 1998, Gallagher et al. 2013, Thuiller et al. 2014). Indeed, the functional space formed by species that should not disappear under the climate change scenario includes those that are expected to completely lose their climatically suitable habitat (Fig. 2a, b, c), hence indicating that these species are not functionally unique at the Mediterranean Sea scale.

At the ecoregion scale, results showed high heterogeneity within some ecoregions such as the Western basin and the Alboran Sea that would lose an higher amount of PD compared to species loss. This disproportional erosion of PD is predicted to occur in ecoregions where resource overexploitation is marked and where few Marine Protected Areas (MPAs) are established, like in the Alboran Sea (Mouillot et al. 2011a). Then, our results suggest that species loss caused by climate warming would not lead to a disproportionate loss of $\mathrm{FD}$ at the ecoregion scale, confirming results obtained at the scale of the whole Mediterranean Sea. In contrast, considering a smaller spatial scale (i.e. the grid cell) showed opposite patterns for the expected loss of FD under the climate warming scenario (Fig. 4f). For instance, disproportionate losses of FD were projected for several areas belonging to the western Mediterranean (e.g. almost all the Gulf of Lion), Adriatic Sea, Aegean Sea and Ionian Sea ecoregions. These findings suggest that the loss of FD in these areas is not offset by the functions provided by those species that are expected to find new suitable climatic conditions.

Overall, these findings obtained at intermediate and small spatial scales (i.e. the marine ecoregions and the grid cells, respectively) have important implications since the functional and phylogenetic components of biodiversity have been largely ignored in climate change impact assessment (but see Thuiller et al. 2011, 2014), and even more in the marine realm. These components have been found to be important drivers of ecosystem functioning (Cadotte et al. 2008,2012 ). For instance, a recent study showed that evolutionarily diverse assemblages enhance ecosystem productivity (Cadotte 2013). Ecosystem functioning and associated services depend on the maintenance of multiple processes across time periods and environmental change scenarios (Isbell et al. 2011), which requires species with complementary functions (Gamfeldt et al. 2008).

From a conservation perspective, the fact that disproportionate losses of PD and FD are projected for several areas of the Mediterranean Sea emphasize that is it important to consider not only the loss of species (Thomas et al. 2004) but also the potential erosion of the other biodiversity facets when assessing the potential effects of climate change at intermediate and local scales. Conservation actions that only focus on maintaining the level of species richness may not completely preserve the evolutionary history and the diversity of functions of impacted fish assemblages, which may in turn affect long-term ecosystem viability (Cadotte et al. 2011). Future conservation efforts should be therefore prioritize areas where $\mathrm{PD}$ and FD of fish assemblages are projected to decline, and more particularly within a climate change context coupled to overexploitation (Hsieh et al. 2008).

Here we did not consider potential colonizations of fish species from neighbouring regions (i.e. the Atlantic Ocean and the Red Sea) or range shifts of currently established exotic fish species under climate warming. We explored the impacts of climate warming on only the native coastal Mediterranean fish fauna. We acknowledge that this may be restrictive but most established exotic fishes are not in distributional equilibrium (Ben Rais Lasram et al. 2008), which is a required assumption for predicting and projecting 
species distributions (Guisan and Thuiller 2005). In addition, a study emphasized that contrary to predictions of an accelerating number of Red Sea fish invasions following increased water temperatures (Ben Rais Lasram and Mouillot 2009), hotter summers in the Mediterranean Sea may prevent the establishment of many Red Sea fishes (Belmaker et al. 2013). Beyond these considerations, several studies showed that currently established exotic fishes have greatly and quickly expanded their ranges across the Mediterranean Sea (Azzurro et al. 2012), while others suggested that Lessepsian fish invasions have locally extirpated several native species in the south-eastern Mediterranean Sea (Edelist et al. 2013). This implies that potential biodiversity erosion of native fish assemblages could be modulated by the expansion of exotic fishes under climate change, the level of functional redundancy between native and exotic fishes or their level of phylogenetic relatedness being the key determinant (Matsuzaki et al. 2013). Overall, we recommend that future studies forecast the future distribution of both native and exotic species in order to provide a synthetic picture of the future of biodiversity under climate change.

In this study we showed that patterns of biodiversity erosion under climate warming should be analyzed at different spatial scales, as disproportionate losses of PD and FD were only forecasted when considering the ecoregion and grid cell scales. In addition, unexpected losses of FD were only forecasted at the grid cell scale while disproportionate declines of PD were forecasted at both the ecoregion and grid cell scales. The issue of spatial scaling is central in ecology and biogeography (Whittaker et al. 2001) and many studies have emphasized that the perception of anthropogenic impacts on biodiversity is scale-dependent (Bartolino et al. 2012, Powell et al. 2013). In regards to climate warming that results in both range expansions and contractions, several studies have showed that these two processes might display different distributional scaling (Wilson et al. 2004). For instance, species can expand their range across coarse spatial scales (i.e. the ecoregion scale in the present study) despite little gain at finer spatial scales (i.e. the grid cell). In contrast, range contractions can cause species loss at coarse spatial scales despite substantial losses at finer spatial scales. Overall, our findings stress the importance of explicitly considering the issue of spatial scale when assessing potential impacts of climate warming on biodiversity (see also Keil et al. 2011).

Acknowledgements - This work was partly funded by the Total Foundation, the 'Fondation pour la Recherche sur la Biodiversité' (project BIODIVMED). CA was supported by a MELS-FQRNT postdoctoral fellowship. DM was supported by a Marie Curie International Outgoing Fellowship (FISHECO) with agreement number IOF-GA-2009-236316. Special thanks to Hedvig Nenzén for her useful comments and corrections on this manuscript and the subject editor whose comments significantly improved the manuscript.

\section{References}

Albouy, C. et al. 2013. Projected climate change and the changing biogeography of coastal Mediterranean fishes. - J. Biogeogr. 40: 534-547.
Allouche, O. et al. 2006. Assessing the accuracy of species distribution models: prevalence, kappa and the true skill statistic (TSS). - J. Appl. Ecol. 43: 1223-1232.

Araújo, M. B. and New, M. 2007. Ensemble forecasting of species distributions. - Trends Ecol. Evol. 22: 42-47.

Azzurro, E. et al. 2012. Fistularia commersonii in the Mediterranean Sea: invasion history and distribution modeling based on presence-only records. - Biol. Invasions 15: 977-990.

Barnosky, A. D. et al. 2011. Has the Earth's sixth mass extinction already arrived? - Nature 471: 51-57.

Bartolino, V. et al. 2012. Scale-dependent detection of the effect of harvesting a marine fish population. - Mar. Ecol. Prog. Ser. 444: 251-261.

Belmaker, J. et al. 2013. Ecological traits and environmental affinity explain Red Sea fish introduction into the Mediterranean. - Global Change Biol. 19: 1373-1382.

Ben Rais Lasram, F. and Mouillot, D. 2009. Increasing southern invasion enhances congruence between endemic and exotic Mediterranean fish fauna. - Biol. Invasions 11: 697-711.

Ben Rais Lasram, F. et al. 2008. Ecological correlates of dispersal success of lessepsian fishes. - Mar. Ecol. Prog. Ser. 363: 273-286.

Ben Rais Lasram, F. et al. 2009. Fish diversity patterns in the Mediterranean Sea: deviations from a mid-domain model. - Mar. Ecol. Prog. Ser. 376: 253-267.

Ben Rais Lasram, F. et al. 2010. The Mediterranean Sea as a 'cul-de-sac' for endemic fishes facing climate change. - Global Change Biol. 16: 3233-3245.

Beuvier, J. et al. 2010. Modeling the Mediterranean Sea interannual variability during 1961-2000: focus on the Eastern Mediterranean Transient. - J. Geophys. Res. 115: C08017.

Buisson, L. et al. 2013. Toward a loss of functional diversity in stream fish assemblages under climate change. - Global Change Biol. 19: 387-400.

Burreson, E. M. and Sypek, J. P. 1981. Cryptobia sp (Mastigophora, Kinetoplastida) from the gills of marine fishes in the Chesapeake Bay. - J. Fish Dis. 4: 519-522.

Cadotte, M. W. 2013. Experimental evidence that evolutionarily diverse assemblages result in higher productivity. - Proc. Natl Acad. Sci. USA 110: 8996-9000.

Cadotte, M. W. et al. 2008. Evolutionary history and the effect of biodiversity on plant productivity. - Proc. Natl Acad. Sci. USA 105: 17012-17017.

Cadotte, M. W. et al. 2011. Beyond species: functional diversity and the maintenance of ecological processes and services. - J. Appl. Ecol. 48: 1079-1087.

Cadotte, M. W. et al. 2012. Phylogenetic diversity promotes ecosystem stability. - Ecology 93: S223-S233.

Coll, M. et al. 2010. The biodiversity of the Mediterranean Sea: estimates, patterns, and threats. - PLoS One 5: e11842.

Dambach, J. and Roedder, D. 2011. Applications and future challenges in marine species distribution modeling. - Aquat. Conserv. 21: 92-100.

Doledec, S. et al. 2000. Niche separation in community analysis: a new method. - Ecology 81: 2914-2927.

Dolnicar, S. et al. 1999. Analyzing destination images: a perceptual charting approach. - J. Travel Tourism Marketing 8: 43-57.

Dulvy, N. K. et al. 2008. Climate change and deepening of the North Sea fish assemblage: a biotic indicator of warming seas. - J. Appl. Ecol. 45: 1029-1039.

Edelist, D. et al. 2013. Restructuring the sea: profound shifts in the world's most invaded marine ecosystem. - Divers. Distrib. 19: 69-77.

ETOPO2v2 2010. Global gridded 2-minute database. - National Geophysical Data Center, National Oceanic and Atmospheric Administration, US Dept of Commerce, <www.ngdc.noaa. gov/mgg/global/etopo2.html> accessed 1 June 2010.

Faith, D. P. 1992. Conservation evaluation and phylogenetic diversity. - Biol. Conserv. 61: 1-10. 
Ferrier, S. and Guisan, A. 2006. Spatial modelling of biodiversity at the community level. - J. Appl. Ecol. 43: 393-404.

Froese, R. and Pauly, D. (eds) 2012. FishBase. - World Wide Web electronic publication, ver. 08/2012.

Gallagher, R. V. et al. 2013. Species loss and gain in communities under future climate change: consequences for functional diversity. - Ecography 36: 531-540.

Gamfeldt, L. et al. 2008. Multiple functions increase the importance of biodiversity for overall ecosystem functioning. - Ecology 89: 1223-1231.

Guisan, A. and Thuiller, W. 2005. Predicting species distribution: offering more than simple habitat models. - Ecol. Lett. 8: 993-1009.

Hsieh, C. H. et al. 2008. Spatial analysis shows that fishing enhances the climatic sensitivity of marine fishes. - Can. J. Fish. Aquat. Sci. 65: 947-961.

Isbell, F. et al. 2011. High plant diversity is needed to maintain ecosystem services. - Nature 477: 199-202.

Keil, P. et al. 2011. Biodiversity change is scale-dependent: an example from Dutch and UK hoverflies (Diptera, Syrphidae). - Ecography 34: 392-401.

Landis, J. R. and Koch, G. G. 1977. Measurement of observed agreement for categorical data. - Biometrics 33: 159-174.

Legendre, P. and Legendre, L. 1998. Developments in environmental modelling. - Elsevier.

Lloyd, M. J. et al. 2012. Physical and biological factors affect the vertical distribution of larvae of benthic gastropods in a shallow embayment. - Mar. Ecol. Prog. Ser. 464: 135-151.

Louisy, P. 2005. Guide d'identification des poissons marins: Europe de l'ouest et Méditerranée. - Ulmer.

Mann, R. H. K. and Blackburn, J. H. 1991. The biology of the eel Anguilla anguilla (L) in an English chalk stream and onteractions with juvenile trout Salmo trutta (L) and salmon Salmo salar (L). - Hydrobiologia 218: 65-76.

Matsuzaki S. S. et al. 2013. Consequences of the introduction of exotic and translocated species and future extirpations on the functional diversity of freshwater fish assemblages. - Global Ecol. Biogeogr. 22: 1071-1082.

Merigot, B. et al. 2010. On goodness-of-fit measure for dendrogram-based analyses. - Ecology 91: 1850-1859.

Meynard, C. N. et al. 2012. A phylogenetic perspective on the evolution of Mediterranean teleost fishes. - PLoS One 7: e36443.

Mouillot, D. et al. 2011a. Protected and threatened components of fish biodiversity in the Mediterranean Sea. - Curr. Biol. 21: 1044-1050.

Mouillot, D. et al. 2011b. Functional structure of biological communities predicts ecosystem multifunctionality. - PLoS One 6: e17476.

Supplementary material (Appendix ECOG-01254 at $<$ www.ecography.org/readers/appendix $>$ ). Appendix 1-2.
Naeem, S. 1998. Species redundancy and ecosystem reliability. - Conserv. Biol. 12: 39-45.

Naeem, S. et al. 2012. The functions of biological diversity in an age of extinction. - Science 336: 1401-1406.

Norling, K. et al. 2007. Importance of functional biodiversity and species-specific traits of benthic fauna for ecosystem functions in marine sediment. - Mar. Ecol. Prog. Ser. 332: 11-23.

Petchey, O. L. and Gaston, K. J. 2002. Functional diversity (FD), species richness and community composition. - Ecol. Lett. 5: 402-411.

Petchey, O. L. and Gaston, K. J. 2006. Functional diversity: back to basics and looking forward. - Ecol. Lett. 9: 741-758.

Powell, K. I. et al. 2013. Invasive plants have scale-dependent effetcs on diversity by altering species area relationships. - Science 339: 316-318.

Robinson, L. M. et al. 2011. Pushing the limits in marine species distribution modelling: lessons from the land present challenges and opportunities. - Global Ecol. Biogeogr. 20: 789-802.

Somot, S. et al. 2006. Transient climate change scenario simulation of the Mediterranean Sea for the twenty-first century using a high-resolution ocean circulation model. - Clim. Dynam. 27: 851-879.

Spalding, M. D. et al. 2007. Marine ecoregions of the world: a bioregionalization of coastal and shelf areas. - Bioscience 57 : 573-583.

Stefansdottir, L. et al. 2010. Groundfish species diversity and assemblage structure in Icelandic waters during recent years of warming. - Fish. Oceanogr. 19: 42-62.

Thomas, C. D. et al. 2004. Extinction risk from climate change. - Nature 427: 145-148.

Thuiller, W. 2004. Patterns and uncertainties of species' range shifts under climate change. - Global Change Biol. 10: 2020-2027.

Thuiller, W. et al. 2009. BIOMOD - a platform for ensemble forecasting of species distributions. - Ecography 32: 369-373.

Thuiller, W. et al. 2011. Consequences of climate change on the tree of life in Europe. - Nature 470: 531-534.

Thuiller, W. et al. 2014. The European functional tree of bird life in face of global change. - Nat. Commun. 5, doi: 10.1038/ ncomms4118

Whittaker, R. J. et al. 2001. Scale and species richness: towards a general, hierarchical theory of species diversity. - J. Biogeogr. 28: 453-470.

Wilson, R. J. et al. 2004. Spatial patterns in species distributions reveal biodiversity change. - Nature 432: 393-396.

Winter, M. et al. 2013. Phylogenetic diversity and nature conservation: where are we? - Trends Ecol. Evol. 28: 199-204. 